\title{
Capillary Rise Determination Using Simplified Image Analysis Method
}

\author{
Harris Ramli $^{1 *}$, Zheng Xian Lee ${ }^{1}$, Mastura Azmi ${ }^{1}$, and Fauziah Ahmad ${ }^{1}$ \\ ${ }^{1}$ School of Civil Engineering, Engineering Campus, Universiti Sains Malaysia, 14300 Nibong Tebal, Pulau Pinang, Malaysia
}

\begin{abstract}
Capillary rise underestimation can reduce the long-term performance of civil engineering projects, especially those concerned with ground moisture, such as basements, roads, dams, and soil barrier liners. According to Peck et al. [1], the grain shape constant in empirical capillary rise estimation relationships varies between 10 and $50 \mathrm{~mm}^{2}$ and can be difficult to assume. Furthermore, the measurement of capillary rise in laboratory settings is also quite challenging because it occurs in the transition zone between saturated and unsaturated soils. This study focused on the application of the simplified image analysis method (SIAM) to capillary rise determination for the assessment of the grain shape constant as proposed by Peck et al. [1]. SIAM is a non-intrusive, non-destructive laboratory technique used to measure the temporal and spatial distribution of water saturation in whole domains. In this study, six onedimensional tests were conducted using a $35 \mathrm{~mm} \times 35 \mathrm{~mm} \times 550 \mathrm{~mm}$ column to simulate capillary rise at fixed groundwater levels. The results show that values smaller than $25 \mathrm{~mm}^{2}$ should be used for coarser sand, whereas values greater than $25 \mathrm{~mm}^{2}$ should be used for finer sand. This study demonstrates that SIAM can be further utilized in studies of unsaturated soil, especially to assess soil saturation changes.
\end{abstract}

\section{Introduction}

The presence of subsurface groundwater always affects civil engineering structures, and this condition requires geotechnical engineers to take additional precautions on any construction work done at saturated layers. Although soil at saturated layers always causes difficulty during design and construction, soil at unsaturated layers is even more complex, usually due to a natural phenomenon called capillary rise.

Capillary rise in soil is the upward movement of water above the groundwater table, which increases soil moisture content. Capillary rise in soil affects a civil engineering project not only during construction, but also throughout the project's service life.

Estimating soil capillarity is important because capillary rise underestimation can reduce the long-term performance of a civil engineering structure and infrastructure. Due to capillary rise, even soil layers far above the groundwater table can become wet, especially those containing fine-grained soil. Capillary rise depends on the soil type present. Clay soils promote the most capillary rise, whereas loose, coarse gravel promotes virtually no upward movement.

Water vapor from capillary rise can penetrate the pores of concrete floors. It then condenses into water once it reaches adjacent air-conditioned spaces. This causes the delamination of finished floor surfaces, mildew, and staining. Besides damaging a building's finishing, each time moisture enters a masonry structure, the water transports diluted salts, which it deposits. This process is called efflorescence and results in a salt crystalline deposit often seen as a white or greyish tint on the surface of concrete. Efflorescence can cause the corrosion of steel, which compromises the integrity of the structure over time.

During design and construction work, engineers usually estimate the height of capillary rise. If the estimated capillary rise would reach the constructed structure, proper mitigation actions must usually be implemented.

Estimation is usually done by considering the soil type at the site or performing correlation calculations. The former estimation method simply assumes that finegrained soil usually has high capillary rise, whereas coarse-grained soil has very little capillary rise. The later method is much more accurate than the former.

A few correlations can be used to estimate capillary rise. One of the earliest equations, which is based on open-tube tests on cohesionless soil by Lane et al. [2], indicates reasonable agreement between measured capillary rise and the value predicted by Terzaghi's equation. The results indicate that maximum capillary rise, $h_{c}$, can be described by a linear function of the natural logarithm of the effective grain size, $D_{10}$, as $h_{c}=$ -990 In $D_{10}-1540$. However, the range of $D_{10}$ values to be used with this formula, $0.006 \mathrm{~mm}$ to $0.2 \mathrm{~mm}$, may not be applicable for sandy soil.

In the implementation of empirical relations, Peck et al. [1] roughly approximated the maximum height, $h_{c}$ $(\mathrm{cm})$, to which water is lifted by the capillary force of a given soil as follows:

\footnotetext{
Corresponding author: cemhr@usm.my
} 


$$
h_{c}=\frac{C}{e D_{10}}
$$

where $e$ is the void ratio, $D_{10}$ is Hazen's effective size in millimeters, and $C$ is an empirical coefficient that depends on the grain shape constant and the surface impurities. Generally, $C$ has a value between 10 and 50 $\mathrm{mm}^{2}$.

Based on the variability of the empirical coefficient $C$, a wide range of capillary rise $\left(h_{c}\right)$ values can be obtained. It is critical to use the right empirical coefficient value when determining the soil sample's capillary height. This value depends on the soil's microscopic properties.

However, to identify a suitable range of values for $C$, three parameters in equation (1) must be determined. Of these parameters, $h_{c}$ seems to be quite challenging and, for some very fine-grained soil, it is almost impossible to determine physically in a laboratory setting.

Therefore, this paper presents an approach to determining the $h_{c}$ value through a laboratory experiment using the simplified image analysis method (SIAM), which can be used to measure the temporal and spatial distribution of fluid saturation in the whole domain of the soil laboratory setup.

\section{Methodology}

\subsection{Simplified Image Analysis Method (SIAM)}

SIAM is a laboratory method that can be used to measure the temporal and spatial distribution of soil saturation in any soil laboratory setup. Because SIAM's main principle is using a camera to take images for analysis, as long as the camera can take a picture, it can be analyzed.

The image analysis concept that has been used for many years in contamination flow studies [3], [4], such as for oil spills. It can be applied in unsaturated soil studies specifically concerning saturation change.

The Simplified Image Analysis Method [5] is a method capable of instantaneously measure the saturation distribution values for water and oil in granular soils for the whole range of large domains.

Using the Beer-Lambert Law of Transmissivity, average optical densities of each matrix element $\left(D_{i}\right)$ are compared with average optical densities for the same domain fully saturated with water $\left(D_{i}^{w}\right)$, oil $\left(D_{i}^{o}\right)$, and completely dry $\left(D_{i}^{d}\right)$, to obtain the saturation distribution matrices for water $\left(\left[S_{w}\right]\right)$ and oil $\left(\left[S_{o}\right]\right)$.

The optical density data is obtained from pictures taken with two consumer-grade digital cameras attached to two different band-pass filters. Thus, this method is considered as a non-intrusive and non-destructive technique to measure temporal and spatial distribution of fluid saturations in the whole domain.

For each digital image, the average optical density $\left(D_{i}\right)$ is defined for the reflected light intensity as shown in equation (2), where $N$ is number of pixels contained in the area of interest and, for a given spectral band $i, d_{j i}$ is optical density of individual pixels, $I_{j i}^{r}$ is intensity of the reflected light given by individual pixel values, and $I_{j i}^{o}$ is intensity of light that reflected by an ideal white surface [6].

$$
D_{i}=\frac{1}{N} \sum_{j=i}^{N} d_{j i}=\frac{1}{N} \sum_{j=i}^{N}\left[-\log _{10}\left(\frac{I_{j i}^{r}}{I_{j i}^{o}}\right)\right]
$$

SIAM obtains the saturation distribution matrices ( $\left[S_{w}\right]$ and $\left.\left[S_{o}\right]\right)$ by comparing average optical densities between matrix element $\left(D_{i}\right)$ and three calibration pictures $\left(D_{i}^{w}, D_{i}^{o}\right.$, and $\left.D_{i}^{d}\right)$, for the same domain.

Usually, the first calibration pictures are taken on the model filled with dry sand $\left(S_{w}=0 \%, S_{o}=0 \%\right)$, the second ones on the same model filled with watersaturated sand $\left(S_{w}=100 \%, S_{o}=0 \%\right)$, and the third ones on the model filled with oil sand $\left(S_{w}=0 \%, S_{o}=100 \%\right)$. Since this study only focusing on one type of fluid, the water-saturated sand and oil-saturated sand is basically the same.

Brilliant Blue FCF dye was used for water in order to enhance visual observation and increase their light absorbance properties. The dye was used at concentrations of $1: 10,000$ by weight, without any noticeable change in the physical properties of water. The dyes are not absorbed or filtered by the soil particles.

The studied domains were photographed using two consumer-grade digital cameras, each one attached to either one of the two different band-pass filters, $450 \mathrm{~nm}$ and $656 \mathrm{~nm}$ wavelengths. The experiment was undertaken in a dark room, and two LED floodlights were installed as a controlled lighting source as shown in Fig. 1.

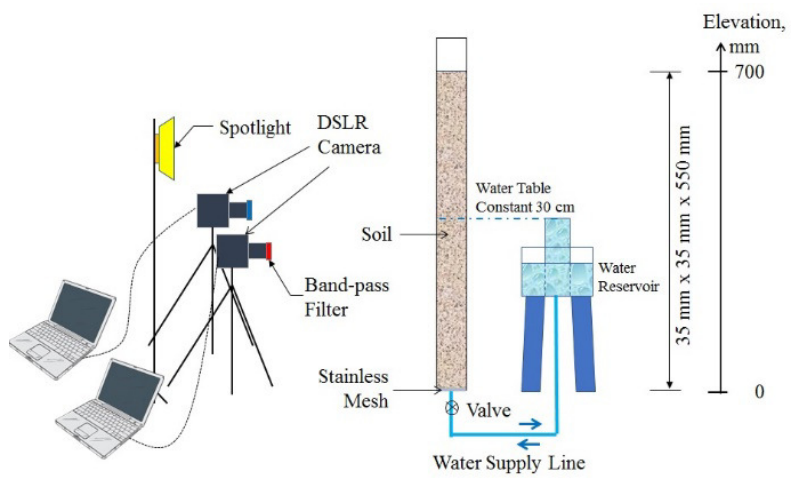

Fig. 1. Column test experimental setup using SIAM.

The light was turned on 30 seconds prior to taking each picture and turned off 30 seconds afterward. A GretagMacbeth ColorChecker Grayscale card was located next to the model to provide a white reference.

All pictures were exported from NEF format (Nikon proprietary RAW version files) to TIFF (Tagged Image File Format) using Nikon ViewNX 2.10.3. The TIFF images were analyzed with an in-house developed program written in MATLAB. The experiments were conducted at Geotechnical Laboratory, School of Civil Engineering, USM. 


\subsection{Materials and Methods}

A $35 \mathrm{~mm} \times 35 \mathrm{~mm} \times 550 \mathrm{~mm}$ one-dimensional column with a transparent glass front wall was designed to study the soil capillarity of quarry sand. The quarry sand was retrieved from Seri Iskandar, Perak, Malaysia, and is widely used in geotechnical and earthwork projects.

The sand's particle size distribution and the upper and lower bounds of the grading limits are shown in Fig. 2. The sand is suitable for construction work, and specifically for the replacement of excavated material, as specified in Standard Specification for Road Work (JKR/SPJ/2013-S2) by Malaysia Public Work Department.

The sand can be classified as SP (poorly graded sand) according to the Unified Soil Classification System. The specific gravity of the sand sample is 2.657 .

The quarry sand was redistributed to three groups, which were original sand $(0.063 \mathrm{~mm}$ to $4.75 \mathrm{~mm})$, coarse sand $(0.600 \mathrm{~mm}$ to $3.35 \mathrm{~mm})$, and medium sand $(0.212$ $\mathrm{mm}$ to $0.600 \mathrm{~mm}$ ), as shown in Fig. 3.

Redistribution was performed to control the sand's effective grain size $\left(D_{10}\right)$ in the experiments. The capillary height of the sand samples in the column apparatus was obtained using Peck et al. [1] capillary rise formula.
The experiment began when the bottom drainage valve was opened, and the fully water-saturated sand was drained until no saturation change occurred. In total, the experiment lasted 18 hours.

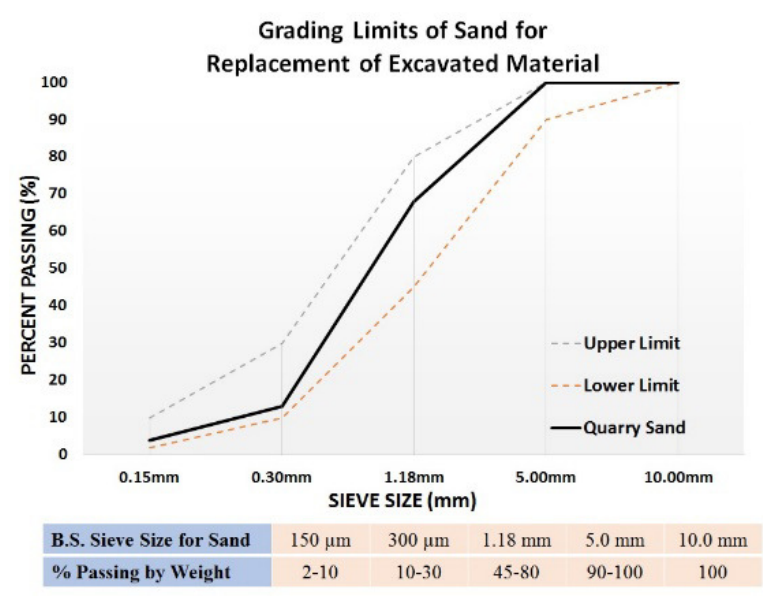

Fig. 2. Sand sample particle size distribution.

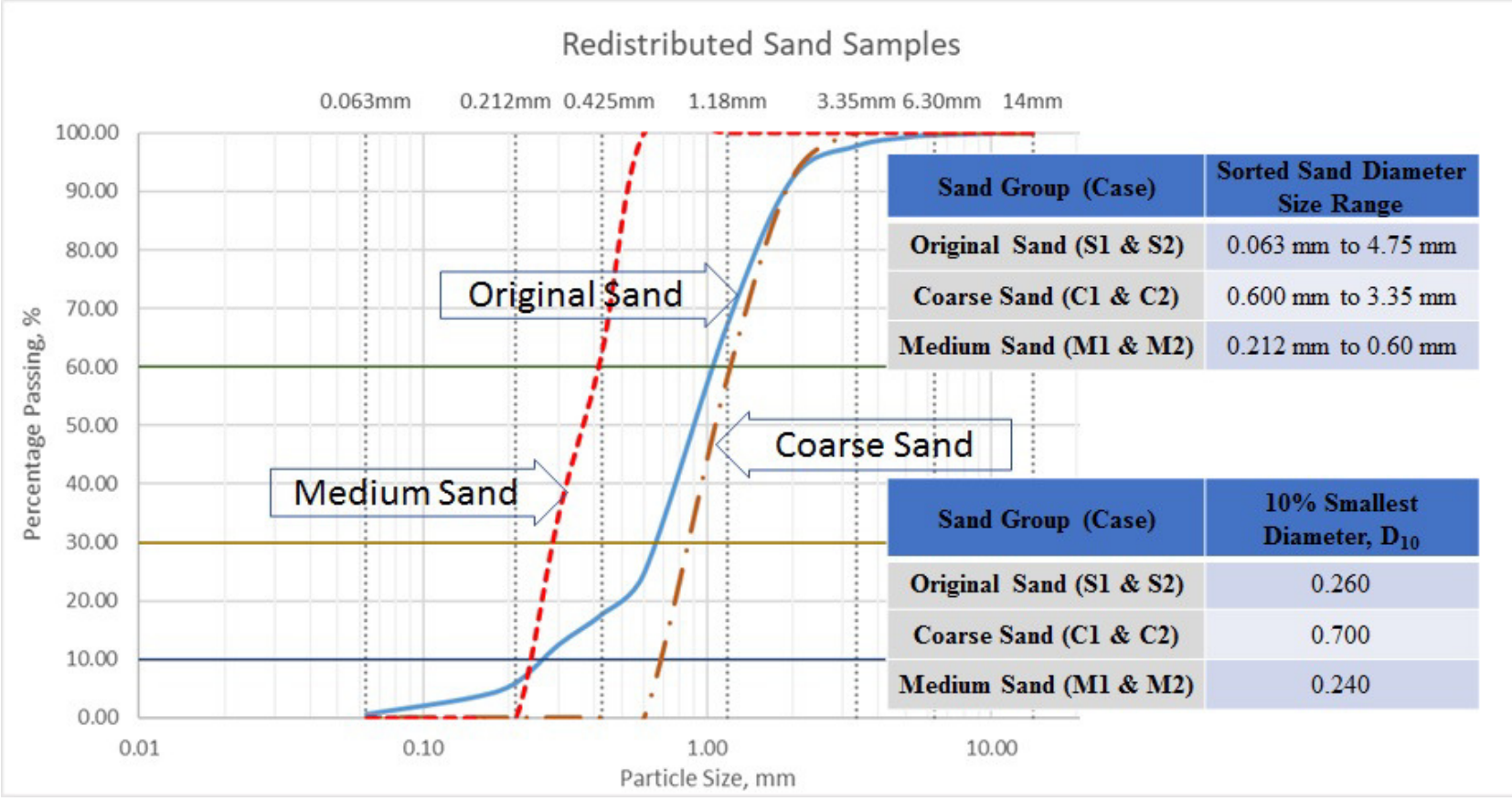

Fig. 3. Particle size distribution for each case.

\section{Results and discussions}

\subsection{Capillarity Fringe Determination}

The height of capillary rise $\left(h_{c}\right)$ can be determined through the capillary fringe $\left(h_{a}\right)$ ratio. The ratio of $h_{c} / h_{a}$ for sandy soil varies from 1.4 to 5 with a few exceptions based on a few parameters [7], [8]. In this study, the capillary height is determined by considering capillary rise, $h_{c}=1.4 h_{a}$. The ratio 1.4 is based on the comparative study by $\mathrm{Lu}$ [8] that considered similar grain size distributions (sample with no gravel and clay) and void ratios.

The height of the capillary fringe $\left(h_{a}\right)$ is determined by measuring the difference between the highest full concentration water content level and the fixed water table. The zone between the water table and the highest full concentration water content level is called the capillary fringe zone. Figs. 4 through 9 show the image analysis distribution for all cases. 
Throughout the experiment, images were captured at least every 15 -minute interval. This means for a single 18-hour experiment, more than 72 images were taken which will provide 72 sets of saturation output data. The huge amount of saturation data need to be studied carefully. Therefore the value is rearranged in a saturation profile based on the height of the column and time.
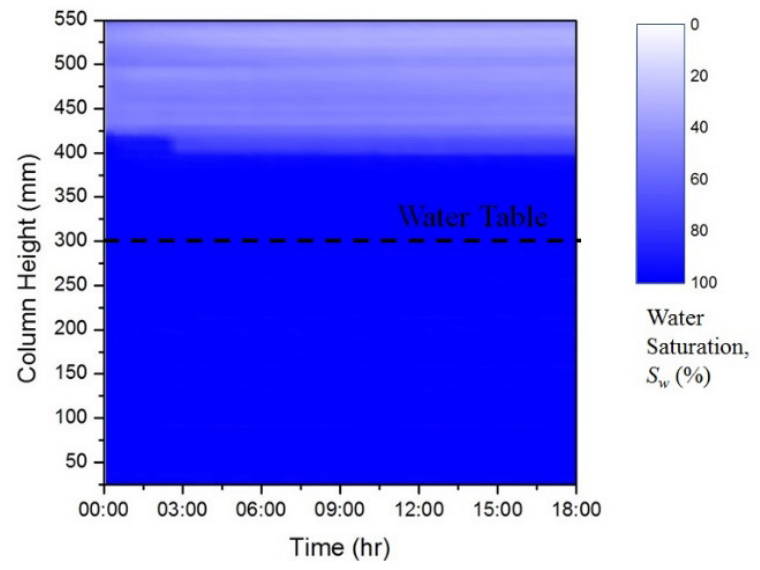

Fig. 4. Water saturation distribution for Case S1.

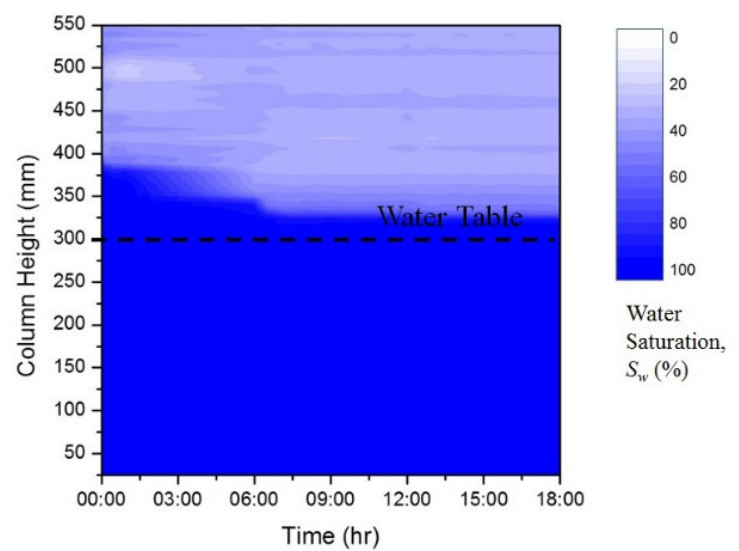

Fig. 6. Water saturation distribution for Case C1.
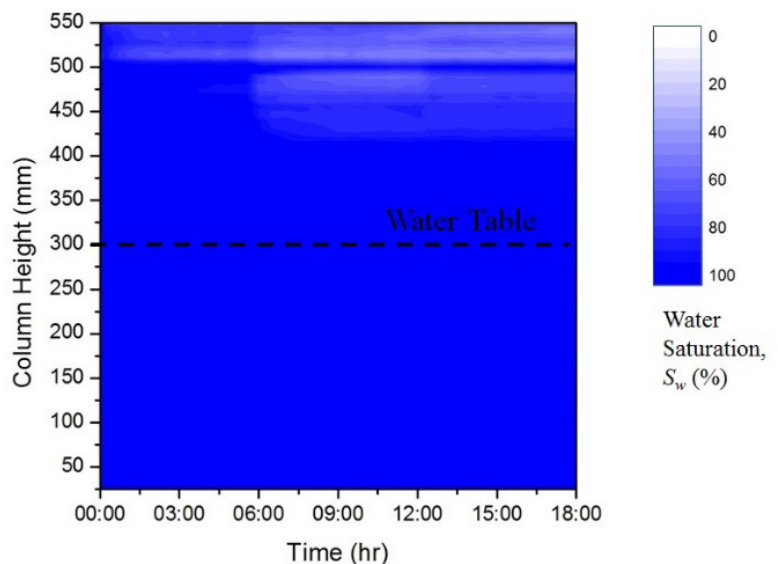

Fig. 8. Water saturation distribution for Case M1.
Since the experiments were conducted using a onedimensional column, the results show the water saturation distribution in vertical direction. The horizontal axis shows the elapsed time during experiment. By using the saturation profile, the changes in water saturation can be studied more accurately according to the elapsed time during experiment.
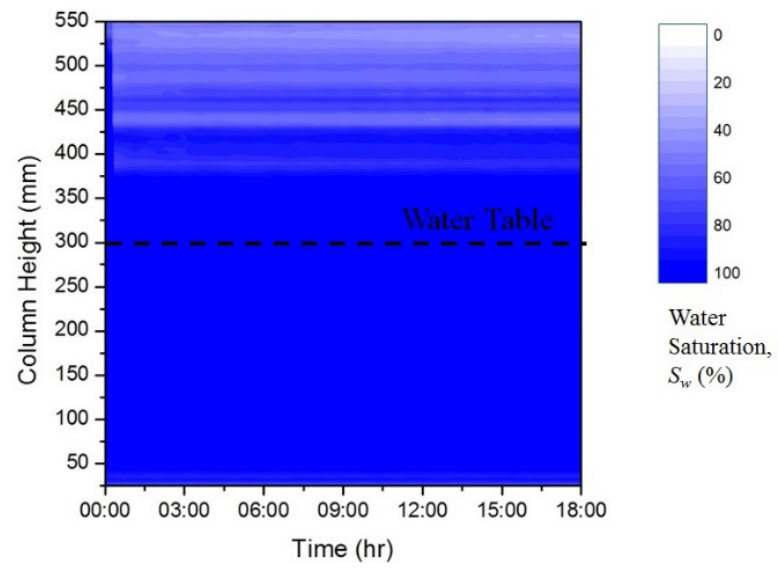

Fig. 5. Water saturation distribution for Case S2.

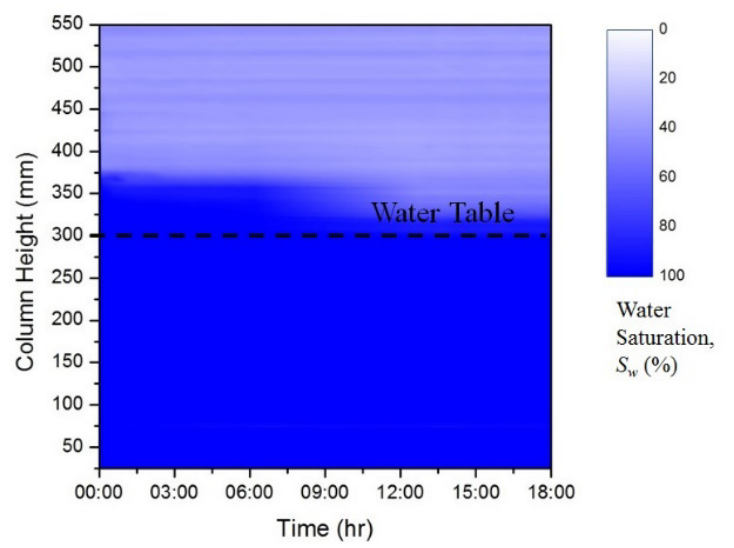

Fig. 7. Water saturation distribution for Case C2.

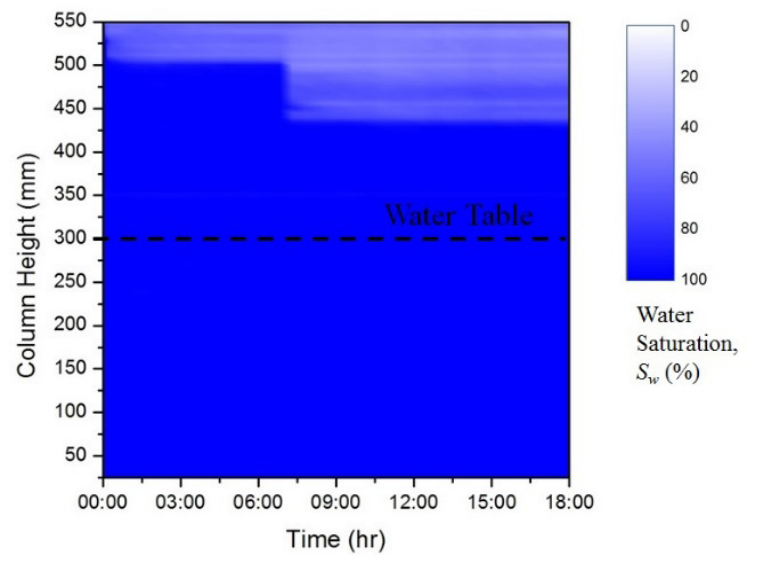

Fig. 9. Water saturation distribution for Case M2. 
From the result it can be seen due to difference in soil effective size, the capillarity behavior are also different. Peck et al. [1] theoretical background for their equation stated that the greater capillary height will rise when the very fine-grained soil materials, but the rate of rise will be much slower due to the low permeability of these materials.

\subsection{Grain Shape Constant Determination}

The grain shape constant, $C$, was estimated using the equation developed by Peck et al. [1]. Based on the estimated grain shape constant values, the respective sand sample's surface and shape are mostly smooth, so it ranges from $16.1 \mathrm{~mm}^{2}$ to $43.8 \mathrm{~mm}^{2}$ (Table 1).

Table 1. Capillary Height Observation Results from Image Analysis.

\begin{tabular}{|c|c|c|c|c|}
\hline Case & $\begin{array}{c}\boldsymbol{D}_{\mathbf{1 0}} \\
(\mathbf{m m})\end{array}$ & $\begin{array}{c}\text { Void } \\
\text { Ratio, } \boldsymbol{e}\end{array}$ & $\begin{array}{c}\text { Capillary } \\
\text { Fringe, } \boldsymbol{h}_{\boldsymbol{a}} \\
(\mathbf{m m})\end{array}$ & $\begin{array}{c}\text { Grain Shape } \\
\text { Constant, } \boldsymbol{C} \\
\left(\mathbf{m m}^{2}\right)\end{array}$ \\
\hline S1 & 0.260 & 0.76 & 90 & 24.9 \\
\hline S2 & 0.260 & 0.76 & 80 & 22.1 \\
\hline C1 & 0.700 & 0.82 & 20 & 16.1 \\
\hline C2 & 0.700 & 0.82 & 20 & 16.1 \\
\hline M1 & 0.240 & 0.87 & 150 & 43.8 \\
\hline M2 & 0.240 & 0.87 & 130 & 38.0 \\
\hline
\end{tabular}

Normally, engineers use the median value of 10 and $50 \mathrm{~mm}^{2}$, which is $25 \mathrm{~mm}^{2}$. However, the results showed that $25 \mathrm{~mm}^{2}$ is not applicable. Based on the results, values smaller than $25 \mathrm{~mm}^{2}$ should be used with coarser sand, whereas values greater than $25 \mathrm{~mm}^{2}$ with finer sand.

The results show that the smaller grain size led to a higher capillary fringe zone, which indicates higher capillary rise. When referring to the estimation equation developed by Peck et al. [1], the void ratio is an important element in determining capillary rise. Pore size affects apparent cohesion, which is the resistance of sand particles to being pulled apart due to the surface tension of the moisture film surrounding each particle.

In general perceptions of capillary rise, it is usually assumed that the grain shape constant should be higher when the effective grain size is small. However, the results show that the soil's grain size distribution plays an important role. In Cases S1 and S2, the effective grain size is similar to that of Cases M1 and M2. However, the grain shape constant of Cases S1 and S2 is much closer to that of Cases $\mathrm{C} 1$ and $\mathrm{C} 2$ because the grain size distribution is similar to that of Cases $\mathrm{C} 1$ and $\mathrm{C} 2$, as shown in Fig. 3.

\section{Conclusion}

This study was conducted to determine a suitable grain shape constant, $C$, for Peck et al. [1] capillary rise formula. This study also demonstrated that saturation changes in unsaturated zones can be determined using SIAM, which was developed by Flores [5]. SIAM is a method capable of instantaneously measuring the saturation distribution values of water in granular soils for the whole range of large domains. Based on the capillarity experiment conducted, when estimating capillary rise using Peck et al. [1] formula, values smaller than $25 \mathrm{~mm}^{2}$ should be used for coarser sand, whereas values greater than $25 \mathrm{~mm}^{2}$ should be used for finer sand. This study demonstrates that SIAM can be further utilized in unsaturated studies, especially for obtaining soil saturation changes.

\section{Acknowledgements}

The authors wish to express sincere appreciation for the support from School of Civil Engineering, Universiti Sains Malaysia for its testing facilities in making this project a success. The research work was funded by the Department of Higher Education, Ministry of Education Malaysia under the Fundamental Research Grant Scheme with grant number FRGS/1/2018/TK01/USM/03/4.

\section{References}

1. R. B. Peck, W. E. Hanson, \& T. H. Thornburn, Foundation engineering (John Wiley \& Sons, New York, 1974)

2. E. W. Lane, C. Brown, G. C. Gibson, C. S. Howard, W. C. Krumbein, G. H. Matthes, W. W. Rubey, A. C. Trowbridge \& L. G. Straub, L. G., 1947. Am. Geophys. Union Trans. 28, 936-938. (1947).

3. C. C. Kechavarzi, K. Soga \& T. H. Illangasekare. J. Contam. Hydrol. 76(3-4), 211-233 (2005)

4. J. P. Tsai, L. C. Chang, S. Y. Hsu \& H. Y. Shan. Environ. Sci. Pollut. Res. 24(35), 26927-26939 (2017)

5. G. Flores, T. Katsumi, T. Inui \& M. Kamon. Soils Found. 51(5), 835-847 (2011)

6. C. Kechavarzi, K. Soga \& P. Wiart. J. Contam. Hydrol. 46(3-4), 265-293 (2000)

7. Q. Liu, N. Yasufuku, J. Miao \& J. Ren. Soils Found. 54(6), 1241-1245 (2014)

8. N. Lu \& W. J. Likos, Unsaturated Soil Mechanics (John Wiley \& Sons, New Jersey, 2004) 